\title{
Molecular and morphological characterisation of the metacercariae of two species of Cardiocephaloides (Digenea: Strigeidae) infecting endemic South African klipfish (Perciformes: Clinidae)
}

\author{
Anja Vermaak ${ }^{1}$, Nico J. Smit ${ }^{1}$ and Olena Kudlai ${ }^{1,2,3}$ \\ ${ }^{1}$ Water Research Group, Unit for Environmental Sciences and Management, North-West University, Potchefstroom, South Africa; \\ ${ }^{2}$ Institute of Ecology, Nature Research Centre, Vilnius, Lithuania; \\ ${ }^{3}$ Institute of Parasitology, Biology Centre of the Czech Academy of Sciences, České Budějovice, Czech Republic
}

\begin{abstract}
South African clinids are a major component of the temperate intertidal regions that are also known to participate in life cycles and transmission of several groups of parasites. However, the knowledge of trematode diversity of these fishes is incomplete. In this study, two species of Clinus Cuvier, the super klipfish Clinus superciliosus (Linnaeus) and the bluntnose klipfish Clinus cottoides Valenciennes, were collected from six localities along the South African coast and examined for the presence of trematodes. Metacercariae of Cardiocephaloides Sudarikov, 1959 were found in the eye vitreous humour and brain of C. superciliosus and in the eye vitreous humour of $C$. cottoides. Detailed analyses integrating morphological and molecular sequence data (28S rDNA, ITS2 rDNA-region, and COI mtDNA) revealed that these belong to two species, Cardiocephaloides physalis (Lutz, 1926) and an unknown species of Cardiocephaloides. This study provides the first report of clinid fishes serving as intermediate hosts for trematodes, reveals that the diversity of Cardiocephaloides in South Africa is higher than previously recorded, and highlights the need for further research to elucidate the life cycles of these trematode species. The broad geographical distribution of Cardiocephaloides spp. was confirmed in the present study based on molecular sequence data. The host-parasite interactions between clinid fishes and metacercariae of Cardiocephaloides are yet to be explored.
\end{abstract}

Keywords: Trematoda, Clinus superciliosus, Clinus cottoides, marine fish parasites, DNA, morphology

Clinids (Perciformes) are common inter- and subtidal shore fishes occurring along the coast of southern Africa and many are endemic to this region (von der Heyden et al. 2011). Clinus superciliosus (Linnaeus), the super klipfish, and Clinus cottoides Valenciennes, the bluntnose klipfish, the subjects of the present study, are abundant resident intertidal fish species and have been the focus of research regarding their diet, biology, reproductive biology and population genetic structure (Bennett et al. 1983, Fishelson et al. 2007, Gon et al. 2007, Fishelson and Gon 2009, Holleman et al. 2012, and references therein).

Being associated with the rocky shore habitat, both species have the potential to play an important role in parasite distribution and life cycles, but this has not been fully investigated yet. To date, $C$. superciliosus and $C$. cottoides have been reported as hosts for four parasitic arthropods, Gnathia africana Barnard, 1914 (Gnathiidae) (Davies and Smit 2001), Caligus mortis Kensley, 1970 (Kensley and Grindley 1973), Caligus labracis Scott, 1902 (Caligidae)
(Barnard 1955) and Elthusa xena Van der Wal, Smit et Hadfield, 2019 (Cymothoidae) (species reported only in C. superciliosus) (van der Wal et al. 2019); two species of intestinal trematodes, Coitocaecum capense Bray, 1987 and Helicometra fasciata (Rudolphi, 1819) (Opecoelidae) (Bray 1987); three species of haemoparasites, Haemogregarina bigemina Laveran et Mesnil, 1901 (Smit and Davies 1999), Haemogregarina curvata Hayes, Smit, Seddon, Wertheim et Davies, 2006 (Haemogregarinidae) (species reported only in C. cottoides) (Hayes et al. 2006), and Trypanosoma nudigobii Fantham, 1919 (Trypanosomatidae) (Hayes et al. 2014); a single trichodinid species, Trichodina clini Fantham, 1930 (Fantham 1930); a single species of leech Zeylanicobdella arugamensis de Silva, 1963 (Piscicolidae) (Hayes et al. 2014); and ten species of myxozoan parasites, of which five have been described, Ceratomyxa cottoidii Reed, Basson, Van As et Dyková, 2007 (Reed et al. 2007), Ceratomyxa dehoopi Reed, Basson, Van As et Dyková, 2007 (Reed et al. 2007), Ceratomyxa obovalis 

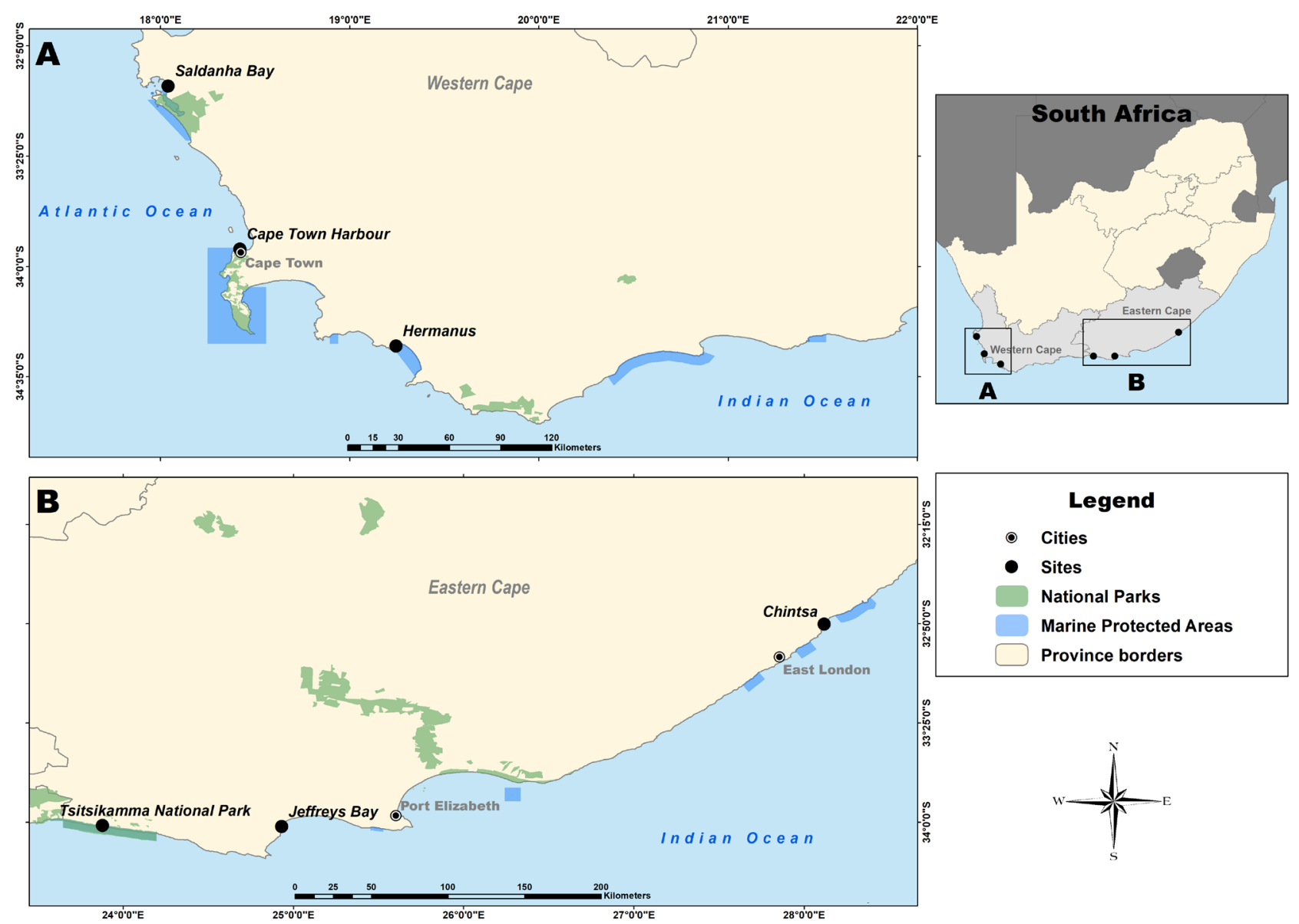

Fig. 1. Map illustrating the sampling localities along the South African coast.

(Fantham, 1930) (Ceratomyxidae) (Fantham 1919, 1930), Sphaeromyxa clini Bartošová-Sojková, Kodádková, Pecková, Kuchta et Reed, 2015 (Sphaeromyxidae) (Bartošová-Sojková et al. 2015), Henneguya clini Reed, Basson, Van As et Dyková, 2007 (Myxobolidae) (Reed et al. 2007) and five molecularly detected undescribed species reported by Bartošová-Sojková et al. (2018).

During a parasitological survey of $C$. superciliosus and C. cottoides along the coast of South Africa, metacercariae belonging to the genus Cardiocephaloides Sudarikov, 1959 were recorded in these fishes. Cardiocephaloides is a genus of the family Strigeidae Railliet, 1919 with merely seven currently recognised species reported from larid birds and penguins around the world (Niewiadomska 2002, Achatz et al. 2020). Species of Cardiocephaloides utilise a three-host life cycle with nassarid and buccinid molluscs as first intermediate hosts, sparid and scomberesocid fish as second intermediate hosts, and seabirds as definitive hosts (Niewiadomska 2002, Donald and Spencer 2016).

To date, Cardiocephaloides longicollis (Rudolphi, 1819 ) is the only species for which all hosts involved in the life cycle are known (Prévot and Bartoli 1980, Osset et al. 2005, Born-Torrijos et al. 2016). One species of this genus, Cardiocephaloides physalis (Lutz, 1926), originally described and reported from the Magellanic penguin Spheniscus magellanicus (Forster) from Uruguayan and Brazilian coasts (Lutz 1926, Dubois 1937, 1938, Brandaõ et al. 2013), was also recorded in the African penguin Spheniscus demersus (Linnaeus) in South Africa (Randall and Bray 1983, Horne et al. 2011, Espinaze et al. 2019). This species has been reported to cause numerous mortalities of penguin chicks. Although the life cycle of $C$. physalis is unknown, there have been several reports on metacercariae of this species in the eyes of the South American pilchard Sardinops sagax (Jenyns) (Reed et al. 2012, Weston et al. 2015, Ukomadu 2017).

Reed et al. (2012) reported metacercariae of 'tetracotyle' type from S. sagax and Weston et al. (2015) found what they thought to be metacercariae of the genus Cardiocephaloides, in particular C. physalis, from the same fish host. Later, metacercariae of this species collected from $S$. sagax by Ukomadu (2017) were molecularly characterised and their identification as $C$. physalis was confirmed by comparison to sequences of adult worms of $C$. physalis reported from $S$. demersus by Horne et al. (2011). Recently, Achatz et al. (2020) cautiously confirmed that C. physalis has a broad distribution, based on $28 \mathrm{~S}$ sequence data of this species from South America and South Africa. However, a better substantiated conclusion required a comparison of data of more variable genes from both continents.

The aim of the present study was to provide the first molecular characterisation associated with morphological descriptions of metacercariae of Cardiocephaloides found in $C$. superciliosus and $C$. cottoides along the coast 
Table 1. Primers used for amplification and sequencing during this study

\begin{tabular}{llll}
\hline Locus & \multirow{2}{*}{ Primer } & Sequence & Reference \\
\hline 28S & Digl2 & 5'-AAG CAT ATC ACT AAG CGG-3' & Tkach et al. (2001) \\
\hline & 1500R & 5'-GCT ATC CTG AGG GAA ACT TCG-3' & Snyder and Tkach (2001) \\
\hline & ECD2 & 5'-CTT GGT CCG TGT TTC AAG ACG GG-3' & Tkach et al. (2003) \\
\hline 300F & 5'-CAA GTA CCG TGA GGG AAA GTT G-3' & Littlewood et al. (2000) \\
\hline ITS1-5.8S-ITS2 & D1 & 5'-AGG AAT TCC TGG TAA GTG CAA G-3' & Galazzo et al. (2002) \\
\hline & D2 & 5'-CGT TAC TGA GGG AAT CCT GGT-3' & Galazzo et al. (2002) \\
\hline ITS2 & 3S & 5'-GGT ACC GGT GGA TCA CGT GGC TAG TG-3' & Morgan and Blair (1995) \\
\hline & ITS2.2 & 5'-CCT GGT TAG TTT CTT TTC CTC CGC-3' & Cribb et al. (1998) \\
\hline COI & DICE1F & 5'-ATT AAC CCT CAC TAA ATT WCN TTR GAT CAT AAG-3' & Van Steenkiste et al. (2015) \\
\hline & DICE14R & 5'-TAA TAC GAC TCA CTA TAC CHA CMR TAA ACA TAT GAT G-3' & Van Steenkiste et al. (2015) \\
\hline
\end{tabular}

of South Africa. We report, for the first time, clinid fishes as intermediate hosts for trematodes in South Africa, including species of Cardiocephaloides. These novel data contribute to our limited knowledge on the life cycles of Cardiocephaloides spp. and the parasite fauna of marine fishes in South Africa.

\section{MATERIALS AND METHODS}

\section{Sample collection}

Eighty-three Clinus superciliosus were collected from six localities along the west and south coasts of South Africa: Saldanha Bay (33.045683S, 18.038628E), Cape Town (33.908092S, 18.418281E), Hermanus (34.421071S, 19.243766E), Tsitsikamma National Park (34.020892S, 23.878674E), Jeffreys Bay (34.026389S, 24.930833E) and Chintsa (32.836538S, 28.116997E) (Fig. 1). In addition, six specimens of Clinus cottoides were collected in Jeffreys Bay. These are geographically distinct areas with varying marine habitats, anthropogenic influences and water temperatures that are affected by the cold Benguela and the warmer Agulhas currents. Sampling was carried out under the permit MALH-K2016-005a for the Tsitsikamma National Park, RES2019-103 for Saldanha Bay, Cape Town harbour and Chintsa, and RES2018/35 for Hermanus and Jeffreys Bay.

Fishes were collected using baited traps and hand lines. Following euthanasia, fishes were subjected to a full helminthological examination and all trematodes found were collected according to Cribb and Bray (2010). After metacercariae were removed from the eye vitreous humour and brain of the host, they were excysted with fine needles and preserved in $96 \%$ molecular grade ethanol. Metacercariae were sorted and selected for further molecular and morphological analyses. Additionally, adult worms of Cardiocephaloides physalis collected by Horne et al. (2011) from Spheniscus demersus and donated to us, were used to generate DNA sequences in order to compare the sequences from adults to sequences of metacercariae collected during the present study. All animal handling, collection and dissections was approved by the North-West University AnimCare Animal Research Ethics Committee (NWU-00565-19-A5).

\section{Morphological analysis}

Photomicrographs of ethanol-preserved metacercariae selected and used for sequencing were taken with a digital camera attached to a Nikon Eclipse $\mathrm{Ni}$ compound microscope (Nikon Instruments, Tokyo, Japan) and analysed with NIS-Elements
BR Camera Analysis software; these served as digital vouchers. Other specimens were stained with Mayer's haematoxylin and mounted on slides with dammar gum or alternatively stained with acetocarmine and mounted on a permanent slide in Berlese's medium. These slides along with the photomicrographs were used to collect morphometric data. All measurements were taken with NIS-Elements BR Camera Analysis software and are given in micrometres $(\mu \mathrm{m})$, unless otherwise stated. The metrical data are presented as the range followed by the mean, while the number of specimens measured (n) is in parentheses. Voucher material has been deposited in the parasite collection of the National Museum (NMB), Bloemfontein, South Africa.

\section{Generation of molecular sequence data}

DNA was extracted using the KAPA Express Extract Kit (KAPA Biosystems, Cape Town, South Africa) and PCRBiosystems Rapid DNA Extraction Kit (PCRBiosystems available from Analytical Solutions, Randburg, South Africa) following the manufacturers' protocols. The latter was modified to utilise only $10 \mu \mathrm{l}$ of lysis buffer and $5 \mu$ of protease containing buffer; recommended procedures for reaction incubation were performed according to the manufacturer's protocol, after which the reaction was diluted with $450 \mu \mathrm{l}$ molecular grade water instead of $900 \mu \mathrm{l}$ as recommended, in order to obtain DNA at a high concentration.

DNA amplification was performed to amplify the partial D1D3 fragment of the 28S nuclear ribosomal RNA gene, either the entire internal transcribed spacer region (ITS1-5.8S-ITS2) or the complete internal transcribed spacer 2 (ITS2) of the ribosomal gene cluster and a partial fragment of the mitochondrial cytochrome $c$ oxidase subunit 1 (COI) gene. Forward and reverse primers specific to each gene/region were used for amplification (Table 1). Amplification was performed by using various polymerase chain reaction (PCR) protocols relevant to each primer as recommended by previous studies (Galazzo et al. 2002, Tkach et al. 2003, Van Steenkiste et al. 2015, Kudlai et al. 2015).

The resultant PCR amplicons were visualised by agarose gel electrophoresis and sent to a commercial sequencing company for purification and sequence generation (Inqaba Biotechnical Industries (Pty) Ltd., Pretoria, South Africa). The obtained sequences were assembled and edited with Geneious v. 11.1.4 bioinformatics software (Biomatters, Auckland, New Zealand). Sequences have been deposited in GenBank. Accession numbers for the sequences of one adult isolate of $C$. physalis are: MW370425 (28S), MW370433 (ITS1-5.8S-ITS2) and MW365507 (COI). Specimens preserved in ethanol have been submitted to the NMB 

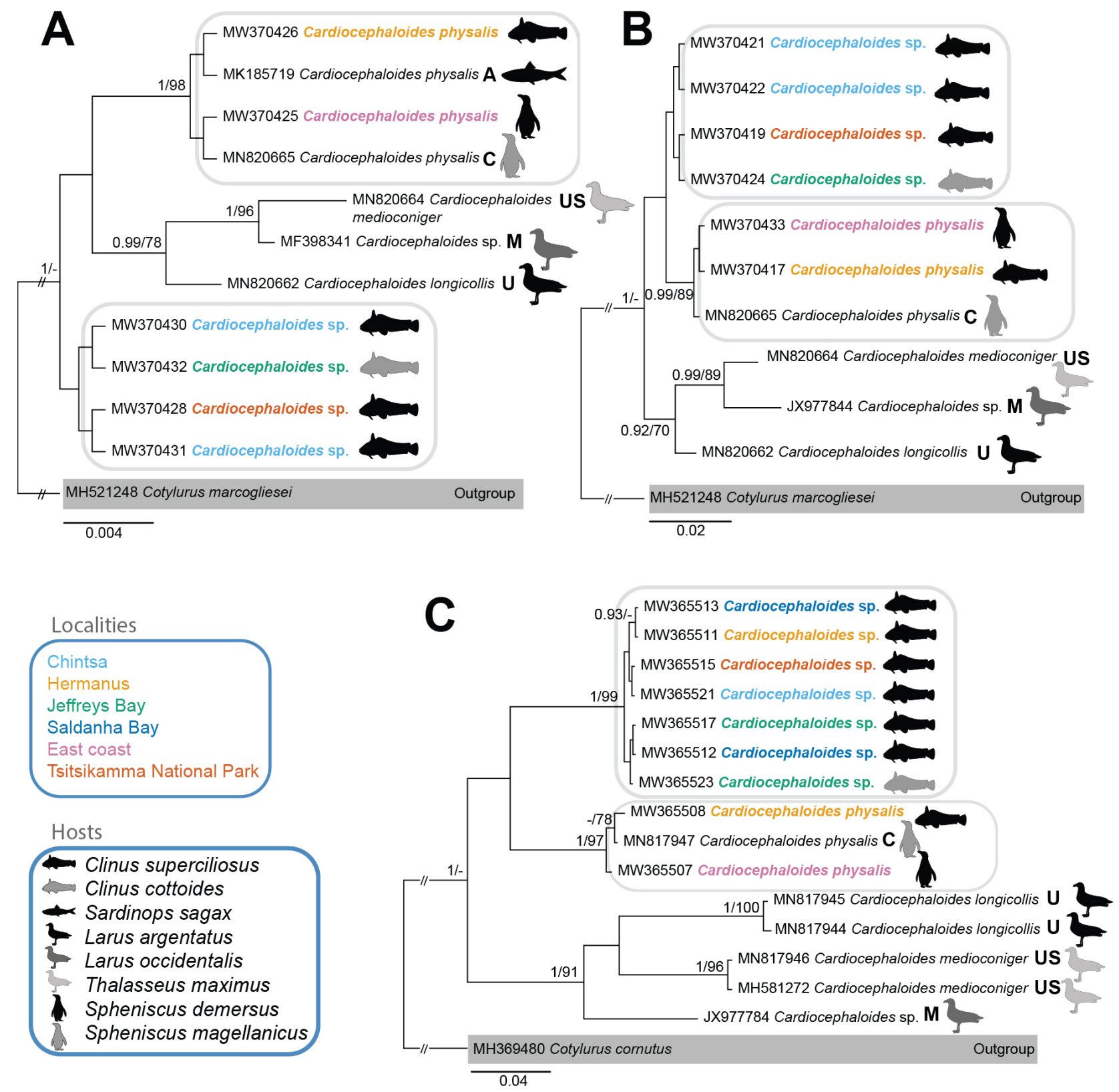

Fig. 2. Bayesian inference (BI) trees based on the $28 \mathrm{~S}$ rDNA (A), ITS2 (B) and COI (C) sequences. Nodal support values are given as BI/ML (maximum likelihood). Support values lower than 0.90 (BI) and 70 (ML) are not shown. The scale bar indicates the expected number of substitutions per site. Newly generated sequences are highlighted in bold. Colours of the species names refer to sampling localities as indicated in the key. Abbreviations: A - Atlantic Ocean, South Africa; C - Chile; M, Mexico; U - Ukraine; US - United States of America.

(P 723). Accession numbers for the sequences of metacercarial isolates are provided in the relevant taxonomic summaries.

\section{Phylogenetic analysis}

In total, 37 novel sequences were generated for 21 metacercarial isolates (seven for 28S, one for ITS1-5.8S-ITS2, eight for ITS2 and 18 for COI) and for one adult isolate (28S, ITS1-5.8SITS2 and COI). Available sequences for representatives of the genus Cardiocephaloides for phylogenetic analyses were retrieved from GenBank as well as sequences for the outgroups (Table 2). Alignments incorporating these sequences and the sequences obtained during the present study were built using MUSCLE (Edgar 2004) as implemented in Geneious v. 11.1.4.
Three alignments were built according to the sequence data of each gene/region. The alignment for the 28S rRNA gene ( 861 nucleotides [nt]) comprised of six newly generated sequences and six sequences obtained from GenBank, including an unpublished sequence for C. physalis (MK185719) obtained from Sardinops sagax in South Africa. The alignment for the ITS2 region (421 nt) consisted of six newly generated sequences and five sequences from GenBank. The third alignment consisted of data for the COI gene (489 nt) for nine newly generated sequences and seven sequences from GenBank. The outgroups for the three alignments were selected based on the results of the phylogenetic analyses of the Diplostomoidea Poirier, 1886 published by Achatz et al. (2020). 


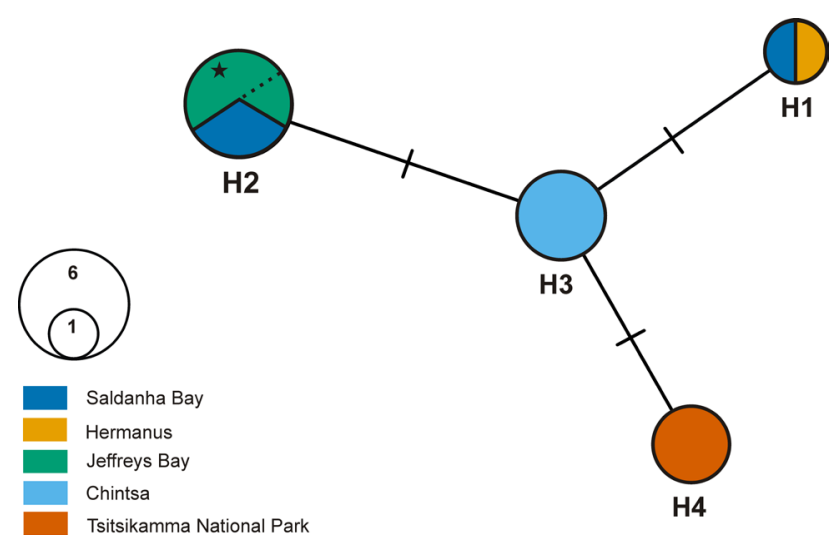

Fig. 3. Haplotype network for Cardiocephaloides sp. based on novel COI sequences from metacercarial isolates collected at five sampling localities along the coast of South Africa from Clinus superciliosus (Linnaeus) and Clinus cottoides Valenciennes. Unsampled intermediate haplotype is represented by short intersecting line; each branch corresponds to a single mutational difference and connective lines represent one mutational step. Circle size is proportional to the number of isolates sharing a haplotype; haplotype frequency is indicated by colourless circles. Isolates obtained from $C$. cottoides are indicated by a star. Abbreviation: $\mathrm{H}$, haplotype. Numbers indicate the haplotype code number (see Table 2 for details).

The best nucleotide substitution model for each alignment was estimated with jModelTest 2.1 (Darriba et al. 2012) according to the Akaike information criterion. The general time reversible model with estimates of invariable sites $(\mathrm{GTR}+\mathrm{I})$ was used to construct the phylogenetic tree for the 28S rDNA; the GTR model with gamma distribution rate variation among sites $(\mathrm{GTR}+\mathrm{G})$ was used to construct the COI phylogenetic tree. The Hasegawa-Kishino-Yano model with gamma distribution rate variation among sites (HKY $+\mathrm{G})$ was used for the construction of the ITS2 phylogenetic tree.

All phylogenetic trees were constructed based on Bayesian inference (BI) and maximum likelihood (ML) estimate analyses. $\mathrm{BI}$ analyses were performed with MrBayes software that was run on CIPRES Science Gateway v. 3.3 (available at https://www. phylo.org/) and ML analyses were performed with PhyML v. 3.0 (available at http://www.atgc-montpellier.fr/phyml/). For the BI analyses of all three alignments, the Markov chain Monte Carlo (MCMC) chains were run for 3,000,000 generations. The 'burnin' was set for the first $25 \%$ of the sampled trees. Nodal support for the ML analyses of all three alignments was estimated by performing 100 bootstrap pseudoreplicates. Trees were visualised using FigTree v. 1.4.3 software (Rambaut 2012). Pairwise genetic distance matrices (p-distances) were calculated with MEGA v. 7. The unique COI haplotypes for a single species from five sampling localities along the South African coast were identified with DnaSP (Rozas et al. 2003). Haplotype networks were reconstructed using the Median-Joining method in PopART software (Population Analysis with Reticulate Trees, http://popart.otago.ac.nz)

\section{RESULTS}

\section{General observations}

In total, 83 Clinus superciliosus from Saldanha Bay (19), Cape Town (16), Hermanus (8), Tsitsikamma National Park (17), Jeffreys Bay (14) and Chintsa (9) were examined for the presence of trematodes. Of these, 21 were found to be infected with metacercariae of the genus Cardiocephaloides. Most metacercariae were present in the eye vitreous humour of fishes, but some were found in the brain of fish from Saldanha Bay $(n=8)$ and Chintsa $(n=1)$. The prevalence and intensity of infection were as follows: Saldanha Bay $(21 \%, 1-2$ in the eyes; $42 \%$, $1-16$ in the brain), Hermanus (2 of 8, 3 individuals in the eyes), Tsitsikamma National Park (29\%, 1-6), Jeffreys Bay $(21 \%, 1-2)$ and Chintsa (3 of 9, 1-8 in the eyes; 1 of 9,76 individuals in the brain). No metacercariae were present in fish collected in Cape Town harbour. Out of six specimens of Clinus cottoides examined from Jeffreys Bay, the eyes of four were infected with 1-6 metacercariae of Cardiocephaloides.

\section{Molecular genetic characterisation of metacercariae}

Newly generated sequences were compared with each other and with sequences of Cardiocephaloides spp. available in GenBank. The novel 28S, ITS2 and COI sequences of the adult Cardiocephaloides physalis were identical with sequences of three metacercarial specimens obtained from the eyes of $C$. superciliosus from Hermanus and with the sequence of metacercariae previously reported from Sardinops sagax in South Africa. All other sequences generated in this study represent another species of Cardiocephaloides.

Further phylogenetic analyses based on the three targeted molecular genetic markers produced trees with a similar topology. In the phylogenetic tree based on the $28 \mathrm{~S}$ rDNA dataset (Fig. 2A), novel sequences of $C$. physalis formed a highly supported clade with sequences of the same species retrieved from GenBank. This clade included novel sequences generated for metacercariae collected from the eyes of $C$. superciliosus in Hermanus and adult worms collected from Spheniscus demersus on the east coast of South Africa, as well as metacercariae collected from the eyes of South American pilchards, S. sagax along the coast of South Africa and adults from Spheniscus magellanicus from Chile. Novel sequences and sequences of C. physalis from GenBank were identical. Four identical sequences of the metacercarial isolates of Cardiocephaloides sp. collected from various localities along the South African coast, formed a separate clade at the basal position to the species of Cardiocephaloides included in the analyses. The interspecific divergence between Cardiocephaloides sp. and four other species of this genus was $0.6-1.2 \%$ (5-10 nt), with $C$. physalis being the least divergent and Cardiocephaloides medioconiger (Dubois et Vigueras, 1949) being the most divergent.

The analyses of the ITS2 dataset showed similar results (Fig. 2B). Sequences for C. physalis of the present study, together with an identical sequence of $C$. physalis from $S$. magellanicus collected in Chile, formed a highly supported clade. Novel sequences for the unknown species of Cardiocephaloides collected from C. superciliosus and C. cottoides clustered together. No intraspecific divergence was observed between ITS2 sequences of this species. The interspecific divergence between Cardiocephaloides sp. and 


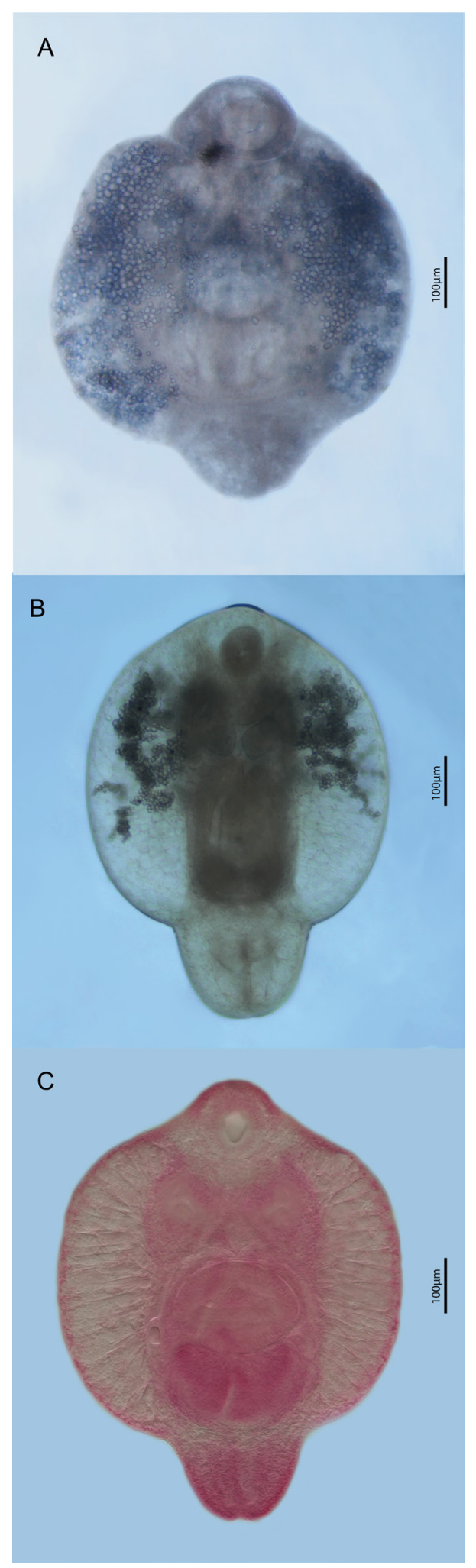

Fig. 4. Photomicrographs of metacercariae of Cardiocephaloides spp. A - Cardiocephaloides physalis (Lutz, 1926) ex Clinus superciliosus (Linnaeus) from Hermanus, excysted, fixed specimen, ventral view (voucher, GenBank MW370427 (28S), MW370418 (ITS2), MW365510 (COI)); B - Cardiocephaloides sp. ex C. superciliosus from Jeffreys Bay, excysted, fixed specimen, ventral view (voucher, GenBank MW365517 (COI)); C - Cardiocephaloides sp. ex Clinus cottoides Valenciennes from Jeffreys Bay, excysted, stained specimen, ventral view (voucher, NMB P 708). other species of Cardiocephaloides in the ITS2 analyses was $0.7-3.6 \%$ (3-15 nt), with $C$. physalis being less divergent and Cardiocephaloides sp. (JX977844) obtained from the western gull, Larus occidentalis Audubon in Mexico, being most divergent. The overall interspecific variation in the ITS2 dataset ranged between $0.7 \%$ and $3.8 \%$ (3-16 nt).

Within the analyses of the COI gene dataset, novel sequences for $C$. physalis clustered with a sequence of this species collected from $S$. magellanicus from Chile in a clade with strong support (Fig. 2C). The intraspecific divergence within this clade was $0.4-0.9 \%(2-4 \mathrm{nt})$ with sequences from South Africa exhibiting the highest sequence divergence. Novel sequences for the unknown species of Cardiocephaloides obtained in the present study formed a strongly supported clade. The intraspecific divergence between the isolates of this species was $0-0.4 \%(0-2 \mathrm{nt})$. Overall interspecific variation between species of Cardiocephaloides in the COI dataset was $8.2-13.2 \%$ (38-61 nt), with $C$. physalis and Cardiocephaloides sp. exhibiting the lowest interspecific divergence and Cardiocephaloides longicollis and Cardiocephaloides sp. (JX977784) showing the highest sequence divergence.

Comparison of ITS1 sequence data between Cardiocephaloides sp. (MW370420) obtained in the present study, with the previously published sequences of Strigeidae sp. (Cardiocephaloides sp. in the analyses of Achatz et al. 2020) (KU695784 - KU695791) demonstrated that Cardiocephaloides sp. from the present study is conspecific to the species from New Zealand (Donald and Spencer 2016). Genetic divergence between sequences of isolates from South Africa and New Zealand was $0.2 \%$ (1 nt).

The 15 COI sequences (625 nt) generated in the present study for isolates of Cardiocephaloides sp. collected at five localities along the coast of South Africa, were collapsed into four haplotypes (Fig. 3). Two of the haplotypes (H1 and H2) found in C. superciliosus in Saldanha Bay (west coast) were detected in two distant localities: H1 in C. superciliosus in Hermanus (south coast) and $\mathrm{H} 2$ (shared with six isolates) in C. superciliosus and C. cottoides in Jeffreys Bay (south coast). Two other haplotypes were recovered in C. superciliosus from Tsitsikamma National Park (H4 shared with three isolates) and in C. superciliosus from Chintsa (H3 shared with four isolates).

\section{Morphological characterisation of metacercariae}

\section{Cardiocephaloides physalis (Lutz, 1926) Fig. 4A}

Description (based on three whole excysted specimens - digital vouchers; metrical data in Table 3). Metacercariae of 'tetracotyle' type, encysted in thin-walled subspherical, colourless, transparent cysts. Body pyriform, indistinctly bipartite, with maximum width just anterior to ventral sucker, body longer than wide. Forebody short, representing $40-41 \%$ (40\%) of body length, larger than hindbody, with ventral concavity. Hindbody more flattened ventrally. Tegument thick, unarmed. Oral sucker transversely oval, muscular, subterminal. Oral opening ventro-subterminal. Pseudosuckers large, elongate-oval, lateral to oesophagus, between oral and ventral suckers. Prepharynx, pharynx, 


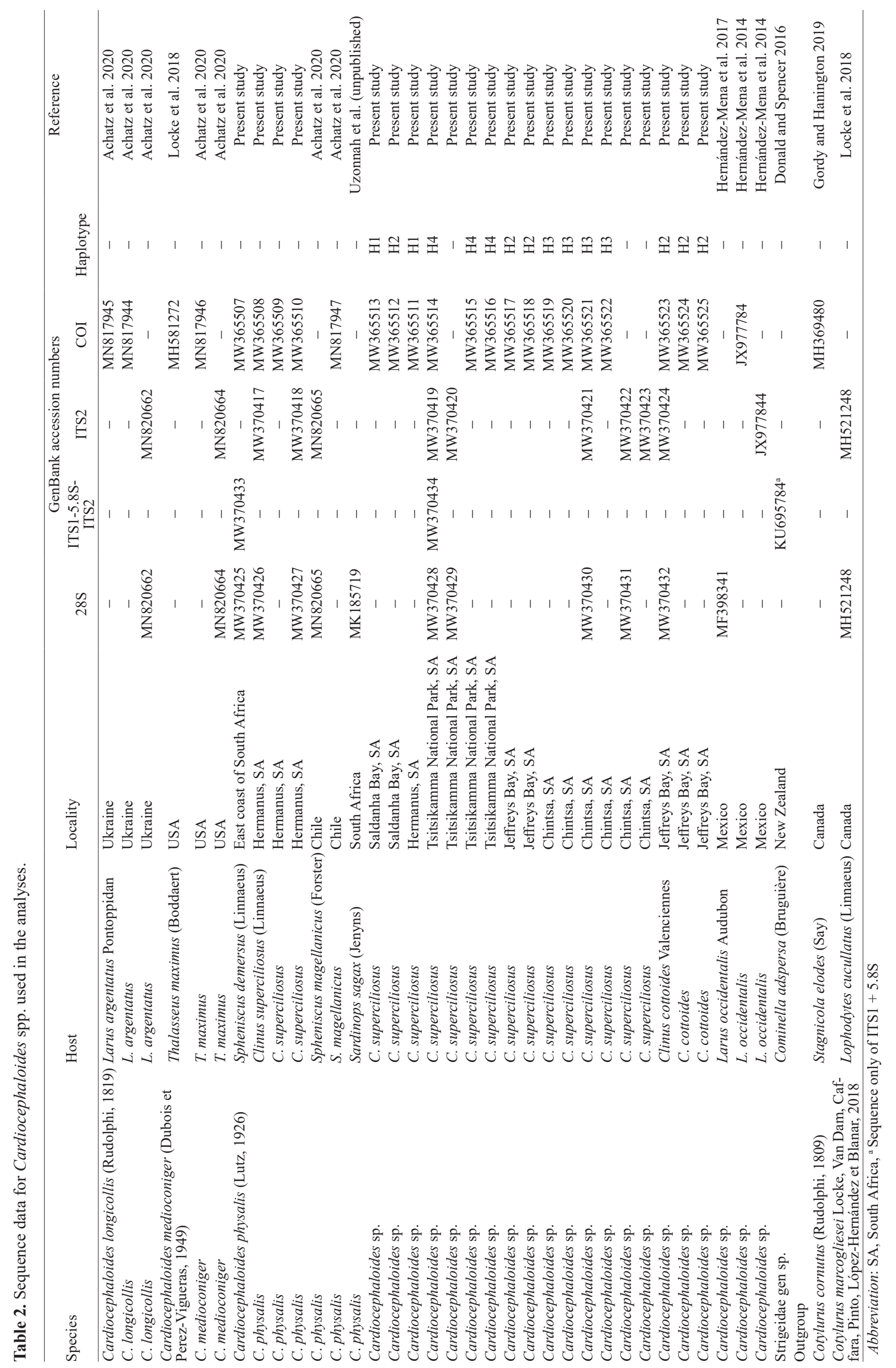


Table 3. Comparative metrical data (in $\mu \mathrm{m}$ ) for Cardiocephaloides spp.

\begin{tabular}{|c|c|c|c|c|c|c|c|c|c|c|}
\hline Species & \multirow{2}{*}{\multicolumn{2}{|c|}{$\begin{array}{c}\text { Cardiocephaloides } \\
\text { physalis (Lutz, 1926) } \\
\text { Clinus superciliosus } \\
\text { (Linnaeus) }\end{array}$}} & \multicolumn{2}{|c|}{$\begin{array}{c}\text { Cardiocephaloides } \\
\text { physalis }\end{array}$} & \multicolumn{2}{|c|}{ Cardiocephaloides sp. } & & \multicolumn{2}{|c|}{ Cardiocephaloides sp. } \\
\hline Host & & & \multicolumn{2}{|c|}{$\begin{array}{l}\text { Sardinops sagax } \\
\text { (Jenyns) }\end{array}$} & \multicolumn{2}{|c|}{$\begin{array}{c}\text { Engraulis anchoita } \\
\text { Hubbs et Marini }\end{array}$} & \multicolumn{2}{|c|}{$\begin{array}{c}\text { Clinus superciliosus, } \\
\text { Clinus cottoides Valen- } \\
\text { ciennes }\end{array}$} & \multicolumn{2}{|c|}{$\begin{array}{l}\text { Clinus superciliosus } \\
\text { Clinus cottoides }\end{array}$} \\
\hline Locality & \multirow{2}{*}{\multicolumn{2}{|c|}{$\begin{array}{c}\text { Hermanus, } \\
\text { South Africa } \\
\text { (present study, digital } \\
\text { vouchers) }\end{array}$}} & \multicolumn{2}{|c|}{$\begin{array}{c}\text { Gansbay, } \\
\text { South Africa }\end{array}$} & \multicolumn{2}{|c|}{ Argentina, Uruguay } & \multirow{2}{*}{\multicolumn{2}{|c|}{$\begin{array}{l}\text { Tsitsikamma, Jeffreys } \\
\text { Bay, South Africa } \\
\text { (present study, digital } \\
\text { vouchers) }\end{array}$}} & \multirow{2}{*}{\multicolumn{2}{|c|}{$\begin{array}{c}\text { Tsitsikamma, Jeffreys } \\
\text { Bay, South Africa } \\
\text { (present study, stained } \\
\text { vouchers) }\end{array}$}} \\
\hline \multirow[t]{2}{*}{ Source } & & & \multicolumn{2}{|c|}{ Ukomadu (2017) } & \multicolumn{2}{|c|}{ Timi et al. (1999) } & & & & \\
\hline & range $(\mathrm{n}=3)$ & mean & range $(n=77)$ & mean & range $(n=25)$ & mean & range $(n=14)$ & mean & range $(n=10)$ & mean \\
\hline Body length & $791-907$ & 861 & $762-967$ & 875 & $550-860$ & 656 & $661-977$ & 793 & $502-1407$ & 866 \\
\hline Body width & $568-787$ & 675 & $512-677$ & 605 & $360-620$ & 468 & $500-740$ & 605 & $272-946$ & 670 \\
\hline Forebody length & $360-363$ & 362 & $249-386$ & 336 & $210-420$ & 194 & $231-474$ & 320 & $208-485$ & 336 \\
\hline Hindbody length & $525-544$ & 535 & $370-440 *$ & $405^{*}$ & $185-310^{*}$ & $244 *$ & $371-648$ & 473 & $291-922$ & 531 \\
\hline Oral sucker length & $116-121$ & 119 & $87-112$ & 104 & $70-110$ & 93 & $76-125$ & 100 & 89-211 & 124 \\
\hline Oral sucker width & $113-130$ & 124 & $92-116$ & 107 & $80-120$ & 97 & $62-136$ & 96 & $66-233$ & 115 \\
\hline Ventral sucker length & $142-160$ & 151 & $122-146$ & 135 & $100-150$ & 132 & $90-186$ & 144 & $122-226$ & 169 \\
\hline Ventral sucker width & $164-196$ & 180 & $121-147$ & 135 & $110-148$ & 133 & $113-205$ & 155 & $124-268$ & 195 \\
\hline Pseudosuckers length & - & - & $165-233$ & - & $109-160$ & 142 & $101-138$ & 120 & $64-234$ & 132 \\
\hline Pseudosuckers width & - & - & $79-116$ & - & - & - & $67-105$ & 87 & $44-197$ & 105 \\
\hline Holdfast organ length & $292(n=1)$ & - & $127-200$ & 172 & $100-200$ & 140 & $191-433$ & 298 & $212-416$ & 300 \\
\hline Holdfast organ width & $319(\mathrm{n}=1)$ & - & $216-321$ & 281 & $240-310$ & 276 & $202-298$ & 246 & $148-363$ & 234 \\
\hline $\begin{array}{l}\text { Body width/ body } \\
\text { length }\end{array}$ & $1: 1.2-1.4$ & $1: 1.3$ & - & - & - & - & $1: 1.1-1.6$ & $1: 1.3$ & $1: 1.3-1.9$ & $1: 1.5$ \\
\hline $\begin{array}{l}\text { Forebody/ body length } \\
\text { as } \%\end{array}$ & $40-41$ & 40 & - & & - & - & $33-51$ & 40 & $33-42$ & 39 \\
\hline $\begin{array}{l}\text { Oral sucker/ ventral } \\
\text { sucker length }\end{array}$ & $1: 1.2-1.4$ & $1: 1.3$ & - & - & - & - & $1: 1-2$ & $1: 1.5$ & $1: 1-1.6$ & $1: 1.4$ \\
\hline $\begin{array}{l}\text { Oral sucker/ ventral } \\
\text { sucker width }\end{array}$ & $1: 1.3-1.5$ & $1: 1.4$ & - & - & - & - & $1: 1.2-2.5$ & $1: 1.6$ & $1: 1.2-2$ & $1: 1.8$ \\
\hline
\end{tabular}

*values represent length of post acetabular region

oesophagus and caeca not observed. Ventral sucker transversely oval, larger than oral sucker; oral/ventral sucker length ratio $1: 1.2-1.4(1: 1.3)$, oral/ventral sucker width ratio $1: 1.3-1.5(1: 1.4)$, at mid-body length or slightly anterior. Distance from anterior extremity of body to ventral sucker 360-363 (362). Holdfast organ large, transversely oval, bipartite, with longitudinal slit-like aperture, contiguous with and partially overlapping ventral sucker ventrally. Excretory system of 'tetracotyle' type, composed of network filling body with free excretory granules in canals. Numerous medium-sized excretory granules distributed in two lateral fields between posterior margin of oral sucker and posterior margin of holdfast organ; fields confluent at the level of ventral sucker. Excretory vesicle not observed. Excretory pore terminal.

Second intermediate host: Super klipfish Clinus superciliosus (Linnaeus) (Perciformes: Clinidae).

L oc ality: Hermanus (34.421071S, 19.243766E), South Africa.

Site of infection: Vitreous humour of eye.

Molecular data: MW370426-MW370427(28S), MW370417 -MW370418 (ITS2), MW365508-MW365510 (COI).

\section{Cardiocephaloides sp.}

Fig. 4B, C

Description (based on 24 whole excysted specimens digital vouchers and stained specimens; metrical data in Table 3). Metacercariae of 'tetracotyle' type, encysted in thin-walled, subspherical, fluid-filled, colourless, transparent cysts. Body pyriform, indistinctly bipartite, with maximum width anterior to ventral sucker, body longer than wide. Forebody short, representing 33-51\% (40\%) of body length of digital voucher specimens and 33-42\% (39\%) of stained specimens, with ventral concavity. Hindbody more flattened ventrally, shorter than forebody. Tegument thick, unarmed. Oral sucker elongate-oval, muscular, subterminal. Oral opening ventro-subterminal. Pseudosuckers large, elongate-oval, lateral to oesophagus, between oral and ventral suckers. Prepharynx absent, pharynx small, subspherical, muscular; oesophagus short, bifurcates at mid-level between pharynx and ventral sucker; intestinal caeca short, narrow, reach posterior to ventral sucker. Ventral sucker transversely oval, distinctly larger than oral sucker; oral/ ventral sucker length ratio $1: 1-2(1: 1.5)$ of digital voucher specimens and $1: 1-1.6(1: 1.4)$ of stained specimens, oral/ventral sucker width ratio $1: 1.2-2.5(1: 1.6)$ of digital voucher and $1: 1.2-2(1: 1.8)$ of stained specimens, at mid-body length or slightly anterior. Distance from anterior extremity of body to ventral sucker 231-474 (320) of digital voucher specimens and 208-485 (336) of stained specimens. Holdfast organ large, transversely oval, bipartite, with longitudinal slit-like aperture between two large lobes, overlapping ventral sucker ventrally, extends beyond anterior and posterior margins of ventral sucker. Excretory system of 'tetracotyle' type, composed of network filling body with free excretory granules in canals. Numerous small excretory granules occupy most of body between posterior margin of oral sucker and level of mid-length of holdfast organ. Excretory vesicle V-shaped. Excretory pore terminal.

Second intermediate hosts: Super klipfish Clinus superciliosus (Linnaeus), Bluntnose klipfish Clinus cottoides Valenciennes (Perciformes: Clinidae).

L o cality: Saldanha Bay (33.045683S, 18.038628E), Hermanus (34.421071S, 19.243766E), Tsitsikamma National 
Park (34.020892S, 23.878674E), Jeffreys Bay (34.026389S, 24.930833E) and Chintsa (32.836538S, 28.116997E), South Africa.

Site of infection: Vitreous humour of eye (C. superciliosus, C. cottoides), brain (C. superciliosus).

Voucher material: 96 voucher specimens deposited in NMB P 706-722: NMB P 706-716 - 11 stained and permanently mounted specimens and NMB P 717-722 - 85 specimens in ethanol.

Molecular data: MW370428-MW370432 (28S), MW370434 (ITS1-5.8S-ITS2), MW370419-MW370424 (ITS2), MW365511-MW365525 (COI).

\section{DISCUSSION}

Cardiocephaloides physalis was known to be the only representative of the genus Cardiocephaloides in South Africa for decades since it was first recorded in Spheniscus demersus - Randall and Bray (1983), Horne et al. (2011), Espinaze et al. (2019). Interestingly, metacercariae of this genus were previously reported by Parukhin $(1968,1975)$, prior to the discovery of adults. This author found encysted metacercariae of Cardiocephaloides sp. (reported as "Tetracotyle sp. larvae") in the vitreous humour of the eyes of 26 Sardinops sagax $(\mathrm{P}=10.6 \%, 1-7$ specimens in the eyes) collected from the waters around South Africa. Later, metacercariae of Cardiocephaloides were found in the same species of pilchards collected along the South African coast by Reed et al. (2012), Weston et al. (2015) and Ukomadu (2017), and recently a 28S rDNA sequence of these metacercariae confirming their identity as C. physalis, was deposited in GenBank (Ukomadu 2017; as Uzonnah et al. unpublished in GenBank).

Our study has revealed that the species diversity within Cardiocephaloides in South Africa is higher than previously known and that the spectrum of their intermediate hosts is not limited to pilchards. With morphological and molecular evidence based on three genetic markers (28S, ITS2 and COI) we report metacercariae of $C$. physalis from Clinus superciliosus and the second species of the genus, Cardiocephaloides sp. parasitising both C. superciliosus and Clinus cottoides along the west and south coasts of South Africa.

Morphologically, specimens of $C$. physalis in our study were consistent with specimens of the same species found in S. sagax by Ukomadu (2017) and specimens described by Timi et al. (1999) as Cardiocephaloides sp. from Engraulis anchoita Hubbs et Marini, suggested to belong to C. physalis. Despite similarities in body size of metacercariae from our material and metacercariae described by Ukomadu (2017) (Table 3), our specimens differed in possessing a more elongate holdfast organ $(292 \mu \mathrm{m} v s$ 127-200 $\mu \mathrm{m}$ ), larger oral (length $116-121 \mu \mathrm{m} v s$ 87-112 $\mu \mathrm{m}$; width $113-130 \mu \mathrm{m} v s$ 92-116 $\mu \mathrm{m}$ ) and ventral (length 142-160 $\mu \mathrm{m} v s$ 122-146 $\mu \mathrm{m}$; width $164-196 \mu \mathrm{m} v s$ 121-147 $\mu \mathrm{m})$ suckers, and in exhibiting higher minima and maxima for body width $(568-787 \mu \mathrm{m} v s$ 512-677 $\mu \mathrm{m})$.

In comparison to the metacercariae of Cardiocephaloides sp. of Timi et al. (1999), our specimens of C. physalis had higher minima and maxima for all dimensions (see Ta- ble 3 for details). These differences can be ascribed to the limited sample size of metacercariae in the present study and variations in maturation of the metacercarial stages from the different studies.

It is interesting that metacercariae of $C$. physalis were found in both an intertidal fish host as well as an offshore fish host from different families. This suggests that the cercariae of this species do not exhibit strict host specificity, infecting a broad spectrum of fish intermediate hosts. However, further studies are required to confirm transmission patterns of this trematode species.

Achatz et al. (2020) confirmed, based on molecular evidence, the broad distribution of C. physalis in both Africa and South America. However, the authors suggested that further comparison of data from faster mutating genes such as the mitochondrial COI gene might provide a better substantiated conclusion. From our COI analyses, it is evident that the species does not exhibit high genetic intraspecific variability $(0.4-0.9 \%)$, even in isolates from distant geographical localities. Thus, C. physalis can indeed be regarded as a single, widely distributed trematode species.

The presence of the second species of Cardiocephaloides, Cardiocephaloides sp. in our material was confirmed by the results of the phylogenetic analyses. Interestingly, based on comparative sequence analysis of the ITS1 region, this species appeared to be conspecific to the species of sporocyst isolates reported from the whelks Cominella adspersa (Bruguière), Cominella glandiformis (Reeve) and Cominella virgata Adams et Adams in New Zealand (Donald and Spencer 2016). This suggests that the distribution of Cardiocephaloides sp. is broader and not restricted to the coast of southern Africa. However, the characterisation of adult specimens is required to identify these larval trematodes to a lower taxonomic level.

To date, three species of Cardiocephaloides were described and reported from Australia and New Zealand (Dubois and Angel 1972): Cardiocephaloides hilli (Johnston, 1904) from Chroicocephalus novaehollandiae (Stephens) (Australia), Cardiocephaloides musculosus (Johnston, 1904) from Chlidonias hybrida (Pallas) and $H y-$ droprogne caspia (Pallas) (Australia), and Cardiocephaloides ovicorpus Dubois et Angel, 1972 from Phalacrocorax varius (Gmelin) (Australia) and Microcarbo melanoleucos brevirostris (Gould) (New Zealand).

Therefore, Cardiocephaloides sp. may either be one of these known species for which adult specimens have not yet been molecularly characterised or represents a new species within the genus. While it is difficult to predict the distribution pathway of this species between the continents at the present stage, our study once again demonstrates that DNA sequencing is an extremely efficient and precise tool of advancing our knowledge not only in species identification, but in geographical distribution of parasites, even if based on their larval stages.

Specimens of Cardiocephaloides sp. from the two clinid species were morphologically relatively similar to, but overall larger than Cardiocephaloides sp. found by Timi et al. (1999). Yet, the pseudosuckers of our specimens from digital vouchers showed slightly lower minima and maxi- 
ma for length than those noted by Timi et al. (1999) (101$138 \mu \mathrm{m} v s$ 109-160 $\mu \mathrm{m})$. Additionally, it is evident that stained specimens of Cardiocephaloides sp. in our material were overall slightly larger than specimens from digital vouchers, with the exception of the holdfast organ width (Table 3). When compared to our specimens of C. physalis, Cardiocephaloides sp. (digital vouchers) was morphometrically similar, but smaller in all body dimensions with the exceptions of the forebody as a proportion of body length (higher maxima, 33-51\% vs 40-41\%) and sucker ratio (higher maxima for length $1: 1-2$ vs $1: 1.2-1.4$ and width $1: 1.2-2.5$ vs $1: 1.3-1.5)$.

Detailed morphological and morphometric analysis of metacercariae of the two species collected in South Africa during the present study demonstrated remarkably little variation that can be used for species differentiation or identification. However, we found a high degree in variability of the number, size and distribution of excretory granules. Excretory granules in metacercariae of C. physalis were medium-sized, dense and distributed in two lateral fields between the posterior margin of the oral sucker and the posterior margin of the holdfast organ, with fields confluent at the level of the ventral sucker (Fig. 4A). In contrast, excretory granules in metacercariae of Cardiocephaloides sp. were small, less dense and distributed between the posterior margin of the oral sucker and the mid-level of the holdfast organ length (Fig. 4B). We could not compare our data to those of Timi et al. (1999) and Ukomadu (2017) as the authors did not describe or illustrate excretory granules in detail, but we suggest that this characteristic can be potentially useful for species delineation prior to molecular identification. Previously, differences in the number, size and distribution of excretory granules were considered in several studies when differentiating between metacercariae of the genus Diplostomum von Nordmann, 1832 (see Shigin 1986, Pérez-del-Olmo et al. 2014, Kudlai et al. 2017).

Due to the simple morphology, distinction between metacercariae of $C$. physalis and Cardiocephaloides sp. is not obvious. Therefore, molecular characterisation is essential for the accurate identification of these species, pointing out the importance of an integrative approach to the study of trematodes (Blasco-Costa et al. 2016), especially their larval stages that do not yet possess various characteristic features (Hoogendoorn et al. 2020).

Four haplotypes of Cardiocephaloides sp. were shared among isolates collected from $C$. superciliosus and C. cottoides in five localities. According to the haplotype analyses, haplotype $\mathrm{H} 1$ was found in C. superciliosus from Saldanha Bay and Hermanus, whereas haplotype H2 was present in Saldanha Bay and Jeffreys Bay (Figs. 1, 3) in both $C$. superciliosus and $C$. cottoides. The haplotype mixture in the geographically distant localities suggests that there is gene flow between populations from the west coast and south-east coast study sites. The low host specificity at the level of host species was illustrated by the presence of haplotype $\mathrm{H} 2$ in both species of Clinus, which agrees with the general rule for specificity of trematodes to their second intermediate hosts (Galaktionov and Dobrovolskij 2003). As H2 is more abundant in Jeffreys Bay, it can be assumed that this is where the haplotype originated and has subsequently spread to Saldanha Bay. This may be due to direct transmission of digenean descendants between these sites via final host migration. Haplotypes $\mathrm{H} 3$ and $\mathrm{H} 4$ were found in Chintsa and Tsitsikamma National Park, respectively. Interesting to note is the complete absence of trematodes from $C$. superciliosus collected in Cape Town harbour, a locality with high commercial fishing activity and anthropogenic influences. Further investigation into the presence of suitable intermediate hosts from this locality or the effects of anthropogenic activity on these parasites might give more insight into this anomaly.

Metacercariae of Cardiocephaloides sp. occurred more frequently and widespread in C. superciliosus, than C. physalis did, which may suggest that infection with $C$. physalis observed in our study was accidental or rather rare. Due to the much higher prevalence and widespread occurrence of metacercariae of $C$. physalis in $S$. sagax along the coast of South Africa (Reed et al. 2012, Weston et al. 2015, Ukomadu 2017), it is most likely that this is their primary host. Intertidal clinid species are likely the preferred second intermediate host for Cardiocephaloides sp. since infection with this trematode species is widespread along the South African coast. However, further research will be needed to confirm this assumption and to elicit the life cycles and host range of these species of Cardiocephaloides.

As nassarid and buccinid molluscs have been reported as first intermediate hosts for species of Cardiocephaloides in the Mediterranean (Osset et al. 2005) and in the waters around New Zealand (Donald and Spencer 2016), respectively, they might be involved in the life cycles of these parasites in southern Africa. There are at least 12 species of the Nassariidae (Mollusca: Gastropoda), namely, Bullia annulata (Lamarck), B. callosa (Wood), B. digitalis (Dillwyn), B. diluta (Krauss), B. laevissima (Gmelin), B. melanoides (Deshayes), B. natalensis (Krauss), B. pura Melvill, B. rhodostoma Reeve, B. tenuis Reeve, B. vittata (Linnaeus) (see Brown 1982), Nassarius kraussianus (Dunker) (see Perissinotto et al. 2014), N. capensis (Dunker), N. arcularia plicatus (Röding), N. niveus (Adams) and N. speciosus (Adams) (see Branch et al. 2007), and six species of the Buccinidae, namely Afrocominella capensis simoniana (Petit de la Saussaye), Burnupena cincta (Röding), B. lagenaria (Lamarck), B. catarrhacta (Gmelin), B. papyracea (Bruguière) and B. pubescens (Küster) (Branch et al. 2007), occurring along the coast of South Africa that can potentially serve as the first intermediate hosts for C. physalis and Cardiocephaloides sp.

Metacercariae of Cardiocephaloides spp. are trophically transmitted to definitive hosts when infected fish are consumed by seabirds (Osset et al. 2005). To date, only $C$. physalis has been reported from penguins, whereas the rest of the species within the genus are known to parasitise birds from the family Laridae that includes gulls, terns and skimmers (Niewiadomska 2002, Hernández-Mena et al. 2014, Achatz et al. 2020). Due to their widespread occurrence along the South African coast, these seabirds along with others such as cormorants may act as definitive hosts for Cardiocephaloides spp. Moreover, members of the Cli- 
nidae were recently reported as a part of the diet of a larid, the great crested tern Thalasseus bergii (Lichtenstein) in the Western Cape, South Africa (Gaglio et al. 2018).

Clinus spp. commonly occupy intertidal habitats, especially rock pools that support a wide diversity of organisms that may act as first or second intermediate hosts for digenean trematodes. Therefore, these fishes are likely potential intermediate and definitive hosts for a variety of trematodes, as they are easily targeted by cercariae and feed on a wide variety of organisms. Thus, it is not surprising that C. superciliosus and C. cottoides were reported as intermediate hosts for trematodes in the present study. Further dedicated research focusing on the role of klipfish in the life cycles of parasites along the coast of southern Africa and their natural range of distribution could potentially lead to numerous and valuable discoveries.

The present study is not only reporting on the diversity of trematodes in marine fishes from South Africa, but also highlights the potential utility of easily accessible species of Clinus infected with eye and brain parasites (metacercariae of Cardiocephaloides spp.) for studying natural host-parasite relationships, in particular parasite manipulation of host behaviour in the marine environment.

Acknowledgements. We would like to express our gratitude to the staff of Two Oceans Aquarium for collecting the fish from Cape Town harbour, Elizabeth C. Horne for donating adult specimens of C. physalis for molecular analyses and members of the North-West University (NWU) Water Research Group (WRG) for their assistance with fish collection and fieldwork. Thanks are due to Anja Erasmus for constructing the map of the sampling sites. This study was supported by a Postdoctoral Fellowship from the NWU, South Africa and a Claude Leon Foundation Postdoctoral Fellowship (2017-2018) to OK. AV was partially funded by the NWU and the National Research Foundation (NRF) of South Africa (grant no. 122640). Fieldwork of this project was also in part funded by the NRF of South Africa (NRF project CSRP190214417495; P.I. K.A. Hadfield). Opinions expressed, and conclusions arrived at, are those of the authors and not necessarily those of the funding bodies. The funders had no role in study design, data collection and analysis, decision to publish, or preparation of the manuscript. This is contribution number 519 from the NWU-WRG.

\section{REFERENCES}

Achatz T.J., Pullis E.E., González-Acuña D., Tkach, V.V. 2020: Phylogenetic relationships of Cardiocephaloides spp. (Digenea, Diplostomoidea) and the genetic characterization of Cardiocephaloides physalis from Magellanic penguin, Spheniscus magellanicus, in Chile. Acta Parasitol. 65: 525-534.

Barnard K.H. 1955: Additions to the Fauna-list of South African Crustacea and Pycnogonida. Ann. S. Afr. Mus. 43: 1-107

Bartošová-Sojková P., Kodádková A., Pecková H., Kuchta R., Reed, C.C. 2015: Morphology and phylogeny of two new species of Sphaeromyxa Thélohan, 1892 (Cnidaria: Myxozoa) from marine fish (Clinidae and Trachichthyidae). Parasitology 142: 660-674.

Bartošová-Sojková P., Lövy A., Reed C.C., Lisnerová M., Tomková T., Holzer A.S., Fiala I. 2018: Life in a rock pool: Radiation and population genetics of myxozoan parasites in hosts inhabiting restricted spaces. PLoS ONE 13: e0194042.

Bennett B., Griffiths C.L., Penrith M. 1983: The diets of littoral fish from the Cape Peninsula. South Afr. J. Zool. 18: 343-352.

Blasco-Costa I., Cutmore S.C., Miller T.L. Nolan M.J. 2016: Molecular approaches to trematode systematics: 'best practice' and implication for future studies. Syst. Parasitol. 93: 295-306.

Born-Torrijos A., Poulin R., Pérez-del-Olmo A., CulurGioni J., Raga J.A., Holzer A.S. 2016: An optimised multi-host trematode life cycle: fishery discards enhance trophic parasite transmission to scavenging birds. Int. J. Parasitol. 46: 745-753.

Branch G.M., Griffiths C.L., Branch M.L., Beckley L.E. 2007: Two Oceans: A Guide to the Marine Life of Southern Africa. Struik Publishers, Cape Town, $360 \mathrm{pp}$.

Brandaõ M., Luque J.L., Scholz T., Kostadinova A. 2013: New records and descriptions of digeneans from the Magellanic penguin Spheniscus magellanicus (Forster) (Aves: Sphenisciformes) on the coast of Brazil. Syst. Parasitol. 85: 79-98.

BraY R.A. 1987: Some helminth parasites of marine fishes of South Africa: family Opecoelidae (Digenea). J. Nat. Hist. 21: 1049-1075.
Brown A.C. 1982: The biology of sandy-beach whelks of the genus Bullia (Nassariidae). Oceanogr. Mar. Biol. Ann. Rev. 20: 309-361.

Cribb T.H., Anderson G.R., Adlard R.D., Bray R.A. 1998: A DNA-based demonstration of a three-host lifecycle for the Bivesiculidae (Platyhelminthes: Digenea). Int. J. Parasitol. 28: 1791-1795.

Cribb T.H., Bray R.A. 2010: Gut wash, body soak, blender and heat-fixation: approaches to the effective collection, fixation and preservation of trematodes of fishes. Syst. Parasitol. 76: 1-7.

Darriba D., Taboada G.L., Doallo R., Posada D. 2012: jModelTest 2: more models, new heuristics and parallel computing. Nat. Methods 9: 772.

Davies A.J., Smit N.J. 2001: The life cycle of Haemogregarina bigemina (Adeleina: Haemogregarinidae) in South African hosts. Folia Parasitol. 48: 169-177.

Donald K., Spencer H. 2016: Host and ecology both play a role in shaping distribution of digenean parasites of New Zealand whelks (Gastropoda: Buccinidae: Cominella). Parasitology 143: 1143-1156.

Dubois G. 1937: Sur quelques Strigéidés. Rev. Suisse Zool. 44: 391-396.

Dubois G. 1938: Monographie des Strigeida (Trematoda). Mém. Soc. Neuchâtel. Sci. Nat. 6: 1-535.

Dubois G., Angel M. 1972: Strigeata (Trematoda) of Australian birds and mammals from the Helminthological collection of the University of Adelaide. Trans. R. Soc. S. Aust. 96: 197-215.

EDGAR R.C. 2004: MUSCLE: multiple sequence alignment with high accuracy and high throughout. Nucl. Acids Res. 32: 1792-1797.

Espinaze M.P.A., Hui C., Waller L., Dreyer F., Matthee S. 2019: Parasite diversity associated with African penguins (Spheniscus demersus) and the effect of host and environmental factors. Parasitology 146: 791-804.

Fantham H.B. 1919: Some parasitic Protozoa found in South Africa-II. S. Afr. J. Sci. 16: 185-191.

Fantham H.B. 1930: Some parasitic Protozoa found in South Africa-XIII. S. Afr. J. Sci. 27: 376-390. 
Fishelson L., Gon O., Holdengreber V., Delarea Y. 2007: Comparative spermatogenesis, spermatocytogenesis, and spermatozeugmata formation in males of viviparous species of clinid fishes (Teleostei: Clinidae, Blennioidei). Anat. Rec. 290: 311-323.

Fishelson L., Gon O. 2009: Comparison of the ovaries and oogenesis of some Australian and South African viviparid clinid fishes (Clinidae, Blennioidei, Perciformes). Environ. Biol. Fish. 86: 527-540.

Gaglio D., Cook T.R., McInnes A., Sherley R.B., Ryan P.G. 2018: Foraging plasticity in seabirds: a non-invasive study of the diet of greater crested terns breeding in the Benguela region. PLoS ONE 13: e0190444.

Galaktionov K.V., Dobrovolskij A.A. 2003: The Biology and Evolution of Trematodes. Kluwer Academic Publishing, Dordrecht, London and Boston, $592 \mathrm{pp}$.

Galazzo D.E., Dayanandan S., Marcogliese D.J., MclaugLIN J.D. 2002: Molecular systematics of some North American species of Diplostomum (Digenea) based on rDNA-sequence data and comparisons with European congeners. Can. J. Zool. 80: 2207-2217.

Gon O., Fishelson L., Delarea Y. 2007: Comparative morphology of the oropharyngeal cavity of clinid fish (Perciformes: Clinidae), with particular attention to the form, number and distribution of taste buds, and dentition. Afr. J. Mar. Sci. 29: 283-298.

Gordy M.A., Hanington P.C. 2019: A fine-scale phylogenetic assessment of digenean trematodes in central Alberta reveals we have yet to uncover their total diversity. Ecol. Evol. 9: 3153-3238.

Hayes P.M., Lawton S.P., Smit N.J., Gibson W.C., Davies A.J. 2014: Morphological and molecular characterization of a marine fish trypanosome from South Africa, including its development in a leech vector. Parasit. Vector. 7: 50.

Hayes P.M., Smit N.J., Seddon A.M., Wertheim D.F., Davies A.J. 2006: A new fish haemogregarine from South Africa and its suspected dual transmission with trypanosomes by a marine leech. Folia Parasitol. 53: 241-248.

Hernández-Mena D.I., García-Prieto L., García-Varela M. 2014: Morphological and molecular differentiation of Parastrigea (Trematoda: Strigeidae) from Mexico, with the description of a new species. Parasitol. Int. 63: 315-323.

Hernández-Mena D.I., García-Varela M., Pérez-Ponce DE LEÓN G.P. 2017: Filling the gaps in the classification of the Digenea Carus, 1863: systematic position of the Proterodiplostomidae Dubois, 1936 within the superfamily Diplostomoidea Poirier, 1886, inferred from nuclear and mitochondrial DNA sequences. Syst. Parasitol. 94: 833-848.

Holleman W., Von der Heyden S., Zsilavecz G. 2012: Delineating the fishes of the Clinus superciliosus species complex in southern African waters (Blennioidei: Clinidae: Clinini), with the validation of Clinus arborescens Gilchrist \& Thompson, 1908 and Clinus ornatus Gilchrist \& Thompson, 1908, and with descriptions of two new species. Zool. J. Linn. Soc. 166: $827-853$.

Hoogendoorn C., Smit N.J., Kudlai O. 2020: Resolution of the identity of three species of Diplostomum (Digenea: Diplostomidae) parasitising freshwater fishes in South Africa, combining molecular and morphological evidence. Int. J. Parasitol. Parasites Wildl. 11: 50-61.

Horne E.C., Bray R.A., Bousfield B. 2011: The presence of the trematodes Cardiocephaloides physalis and Renicola sloanei in the African Penguin Spheniscus demersus on the east coast of South Africa. Ostrich 82: 157-160.

Kensley B., Grindley J.R. 1973: South African parasitic Copepoda. Ann. S. Afr. Mus. 62: 69-129.

Kudlai O., Cutmore S.C., CribB T.H. 2015: Morphological and molecular data for three species of the Microphallidae (Trematoda: Digenea) in Australia, including the first descriptions of the cercariae of Maritrema brevisacciferum Shimazu et Pearson, 1991 and Microphallus minutus Johnston, 1948. Folia Parasitol. 62: 053 .
Kudlai O., Oros M., Kostadinova A., Georgieva S. 2017: Exploring the diversity of Diplostomum (Digenea: Diplostomidae) in fishes from the River Danube using mitochondrial DNA barcodes. Parasit. Vector. 10: 592.

Littlewood D.T.J., Curini-Galletti M., Herniou E.A. 2000: The interrelationships of Proseriata (Platyhelminthes: Seriata) tested with molecules and morphology. Mol. Phylogenetics Evol. 16: 449-466.

Locke S.A., van Dam A., Caffara M., Pinto H.A., Lópex-Hernández D., Blanar C. 2018: Validity of the Diplostomoidea and Diplostomida (Digenea, Platyhelminthes) upheld in phylogenetic analysis. Int. J. Parasitol. 48: 1043-1059.

Lutz A. 1926: Strigea physalis, n. sp., parasite de Spheniscus magellanicus (avec démonstration des parasites in situ et sur les préparations). C. R. Séances Soc. Biol. 96: 475-476.

Morgan J.A.T., BLAIR D. 1995: Nuclear rDNA ITS sequence variation in the trematode genus Echinostoma: an aid to establishing relationships within the 37-collar-spine group. Parasitology 111: 609-615.

Niewiadomska K. 2002: Family Strigeidae Railliet, 1919. In: D.I. Gibson, A. Jones R.A. Bray (Eds.), Keys to the Trematoda, Volume 1. CAB International, Wallingford, and The Natural History Museum, London, pp. 231-241.

Osset E.A., Fernández M., Raga J.A., Kostadinova A. 2005: Mediterranean Diplodus annularis (Teleostei: Sparidae) and its brain parasite: unforeseen outcome. Parasitol. Int. 54: 201-206.

Paruk hin A.M. 1968: [Helminth fauna of fishes of South Atlantic.] Biologiya Morya 14: 96-113. (In Russian.)

Parukhin A.M. 1975: [Special features of the helminth fauna of Clupeiformes in Southern Seas.] Trudy Biologo-Pochvennogo Instituta, Novaya Seriya 26: 143-151. (In Russian.)

Pérez-del-Olmo A., Georgieva S., Pula H.J., Kostadinova A. 2014: Molecular and morphological evidence for three species of Diplostomum (Digenea: Diplostomidae), parasites of fishes and fish-eating birds in Spain. Parasit. Vector. 7: 502.

Perissinotto R., Miranda N.A.F., Raw J.L., Peer N. 2014: Biodiversity census of Lake St Lucia, iSimangaliso Wetland Park (South Africa): gastropod molluscs. Zookeys 440: 1-43.

Prévot G., Bartoli P. 1980: Demonstration of existence of a marine cycle in the strigeids: Cardiocephalus longicollis Szidat, 1928 (Trematoda: Strigeidae). Ann. Parasitol. Hum. Comp. 55: 407-425.

Rambaut A., Suchard M.A., Xie D., Drummond A.J. 2012: FigTree v1.4.3. Available from: http://tree.bio.ed.ac.uk/software. figtree. Accessed 24 February 2020.

Randall R.M., Bray R.A. 1983: Mortalities of jackass penguin Spheniscus demersus chicks caused by trematodes worms Cardiocephaloides physalis. South Afr. J. Zool. 8: 45-46.

Reed C., MacKenzie K., van der Lingen C.D. 2012: Parasites of South African sardines, Sardinops sagax, and an assessment of their potential as biological tags. Bull. Eur. Assoc. Fish Pathol. 32: 41-48.

Reed C.C., Basson L., VAN As L.L., Dyková I. 2007: Four new myxozoans (Myxosporea: Bivalvulida) from intertidal fishes along the south coast of Africa. Folia Parasitol. 54: 283-292.

Rozas J., Sanchez-DelBarrio J.C., Messeguer X., Rozas R. 2003: DnaSP, DNA polymorphism analyses by thecoalescent and other methods. Bioinformatics 19: 2496-2497.

Shigin A.A. 1986: [Trematode Fauna of the USSR. Genus Diplostomum. Metacercariae.] Nauka, Moscow, 253 pp. (In Russian.)

Smit N.J., Davies A.J. 1999: New host records for Haemogregarina bigemina from the coast of southern Africa. J. Mar. Biol. Assoc. U.K. 79: 933-935.

SNyder S.D., TKaсн V.V. 2001: Phylogenetic and biogeographical relationships among some Holarctic frog lung flukes (Digenea: Haematoloechidae). J. Parasitol. 87: 1433-1440.

Timi J.T., Martorelli S.R., Sardella N.H. 1999: Digenetic trematodes parasitic on Engraulis anchoita (Pisces: Engraulidae) from Argentina and Uruguay. Folia Parasitol. 46: 132-138. 
TKach V.V., Littlewood D.T.J., Olson P.D., Kinsella J.M., SWIDERSKi Z. 2003: Molecular phylogenetic analysis of the Microphalloidea Ward, 1901 (Trematoda: Digenea). Syst. Parasitol. 56: $1-15$.

Tкасн V.V., Snyder S.D., Swiderski Z. 2001: On the phylogenetic relationship of some members of Macroderoididae and Ochetosomatidae (Digenea, Plagiorchioidea). Acta Parasitol. 46: 267-275.

UKomadU N.M. 2017: Assessment of the population structure of the South African sardine Sardinops sagax using a multi-method approach and morphological and molecular characterization of a stock discriminating digenean parasite biotag of the genus Cardiocephaloides. PhD thesis, University of Cape Town, 267 pp.

Van Steenkiste N., Locke S.A., Castelin M., Marcogliese D.J., Аввотт C.L. 2015: New primers for DNA barcoding of digeneans and cestodes (Platyhelminthes). Mol. Ecol. Resour. 15: $945-952$.

Von der Heyden S., Bowie R.C.K., Prochazka K., Bloomers P., Crane N.L., Bernardi G. 2011: Phylogeographic patterns and cryptic speciation across oceanographic barriers in South African intertidal fishes. J. Evol. Biol. 24: 2505-2519.

van der Wal S., Smit N.J., Hadfield K.A. 2019: Review of the fish parasitic genus Elthusa Schioedte \& Meinert, 1884 (Crustacea, Isopoda, Cymothoidae) from South Africa, including the description of three new species. Zookeys 841: 1-37.

Weston L.F., Reed C.C., Hendricks M., Winker H., van der Lingen C.D. 2015: Stock discrimination of South African sardine (Sardinops sagax) using a digenean parasite biological tag. Fish. Res. 164: 120-129.

Cite this article as: Vermaak A., Smit N.J., Kudlai O. 2021: Molecular and morphological characterisation of the metacercariae of two species of Cardiocephaloides (Digenea: Strigeidae) infecting endemic South African klipfish (Perciformes: Clinidae). Folia Parasitol. 68: 007. 